\title{
Creating Designs through Mathematical Functions
}

\author{
Joseph Marfo \\ Lecturer, School of Technology, Christ Apostolic \\ University College
}

\author{
Ezekiel Mensah Martey \\ Lecturer, School of Technology, Christ Apostolic \\ University College
}

\begin{abstract}
This study aims at generating textile patterns and innovative artistic and constructional designs for the artists and architects. It is the development of programming procedure for the analysis and designs of textile patterns and artistic instructional designs. The programming procedure utilizes MATLAB graphics tools for coding program which uses mathematical functions as input(s). The graphs of the functions are animated through several frames of iterations which eventually turn into designs. Trigonometric functions, hyperbolic functions, elliptical functions, parabolic functions and polar functions are inputs of the program. Every step of the iteration generates beautiful design.

Most of the designs were found to be patterns for clothing, tiles, wall clothes, dresses, logo and other textile materials. Other designs were found ideal for artistic works. It must be noted that the designs generated are new and valuable patterns for textiles. They are also valuable innovative designs for artistic technology and also for other purposes.
\end{abstract}

\section{Keywords}

Trigonometric functions, Matlab, Pattern Designs, 3-D Graphics

\section{INTRODUCTION}

Many people ideology about mathematics is ordinary addition, subtraction, division and multiplication of numbers and algebraic expressions. In real-life situations, mathematics stands tall in solving real-life problems and also making projections into the future for decision making purposes.

Textiles designs are another aspect of these problems that mathematics is applied. Many world designers are becoming short of ideas of spectacular designs. Sometimes they spend a lot of time for a design to be developed. Developing patterns for textiles are challenges for textile industries nowadays. Some do copy other peoples' patterns thereby committing plagiarism. Many artistic designs are also difficult to be developed for decorations and others. Constructional and architectural designs are of no exceptions. Sometimes building contractors and architects may lack innovative ideas to decorate buildings, houses etc

\section{PROBLEM STATEMENT}

The textile industry pattern development is a major challenge for the industry nowadays. The minimization of the commitment of plagiarism in the industry is a crucial issue. The artist work for decorating cities and villages take long time to be developed and most of them are lacking ideas. The instructional designs and innovative modeling of contractors and architects are becoming more expensive.

\section{SIGNIFICANCE OF THE STUDY}

The results of this study will create designs and structures for knitted, woven, non-woven of fabrics etc. These involve producing patterns for cloth used in clothing household textiles (such as towels) and decorative textiles such as carpets, curtains. They could be used for decorating tiles for constructional work, inner rooms decorations etc. This study displays mathematical designs using mathematical functions such as trigonometry, ellipse, hyperbola, parabola and polar functions. Mathematical program of MATLAB graphic tools produces the designs which can be used as patterns for textiles, artists' instructional designs and others. The program generates several designs from several iterations of the MATLAB graphic tools provided the function(s) is/are input in the program.

\section{BACKGROUND LITERATURE}

Mathematics is beautiful. This may sound absurd to people who wince at numbers and equations [7]. Because of its beautiful nature, mathematics has been a part of art and architectural designs for ages. Today, most professional textile designers use some form of computer-aided design software. Some of the latest advances in textiles printing have been in the area of digital printing which is full of mathematical programs [3]. [10]Used trigonometric functions to design a thrilling Roller Coaster. Knitted mathematical objects include the platonic solids, Klein bottles and boys' surface. The Lorenz manifold and the hyperbolic plane have been crafted using crochet [15]. Crocheting adventure with hyperbolic planes won the 2009 diagram prize for oddest title of the year. Embroidery techniques such as counted-thread embroidery including cross-stitch and some canvas work methods such as Bargello (needlework) make use of the natural pixels into geometric designs. Ada Dietz (1882-1950) was an American weaver best known for her 1949 monograph algebraic expressions in hand-woven textiles which defines weaving patterns based on the expansion of multivariate polynomials [4]. [12]Presented the rule 90 cellular automation to design tapestries depicting both trees and abstract patterns of triangles. The silk scarves from DMCK designs 2013 collection are based on space-filling curve patterns that Dong Mckenna has devised [5]. His designs are either generalized peano curves or based on a new space-filling construction technique. His design techniques are described in short papers available in the bridges [11]. [13] Observed collections that featured designs from a collaboration between fashion designer Dai Fu-Jiwara and mathematician William Thurston [13]. The designs were inspired by Thurston's geometrization conjecture. The statement of Thurston that every manifold can be decomposed into pieces with one of the eight different uniform geometries, a proof of which had been sketched by Gregori Perelman as part of his proof of the Pointcare conjecture as cited in [7 ].

\section{METHODOLOGY 5.1 MATLAB Graphics}

MATLAB graphics was the setting used to develop the designs. MATLAB has several high-level graphical routines. 
They allow a user to create various graphical objects including two-and three-dimensional graphs, graphical user interfaces (GUIs), movies etc.

\subsection{2-D, 3-D graphics}

Basic function used to create 2-D graphs is the plot function. The function takes a variable number of inputs arguments. Furthermore, MATLAB has several built-in functions for plotting three-dimensional objects. It deals mostly with functions used to plot curves in space (plot 3), mesh surfaces (mesh), surfaces(surf) and contour plots(contour). Plot 3 takes three input parameters-arrays holding coordinates of points on the curve to be plotted. Function mesh is intended for plotting graphs of the 3-D mesh surfaces. To plot the graph of the mesh surface together with the contour plot beneath the plotted surfaces, use function meshc. Function surf is used to visualize data as a shaded surface.

To control the flow of commands in 2-D and 3-D planes, 'for' loop was used. The commands between the 'for' and 'end' statements are executed for all values stored in the array. MATLAB has several colors which were used to plot graphs of the designs. The colors are y for yellow, $\mathrm{m}$ for magenta, $\mathrm{c}$ for cyan, $\mathrm{r}$ for red, $\mathrm{g}$ for green, $\mathrm{b}$ for blue, $\mathrm{w}$ for white and $\mathrm{k}$ for black.Sequence of functional graphs are set into motion. In other words movie function was used.

\subsection{Main Structure of the Program Design}

\subsubsection{Algorithm}

1. Set movie-in function (m)

2. Plot the $x$-axis (scale) and with $y$ axis as default

3. Iterate using h1_line variable which holds the function

4. Grid the graph

5. Label the $\mathrm{x}$ axis of the graph

6. Convert kth number to string

7. Getframe from the iterated functions

8. Movie the function (m)

\subsubsection{Structural Framework}

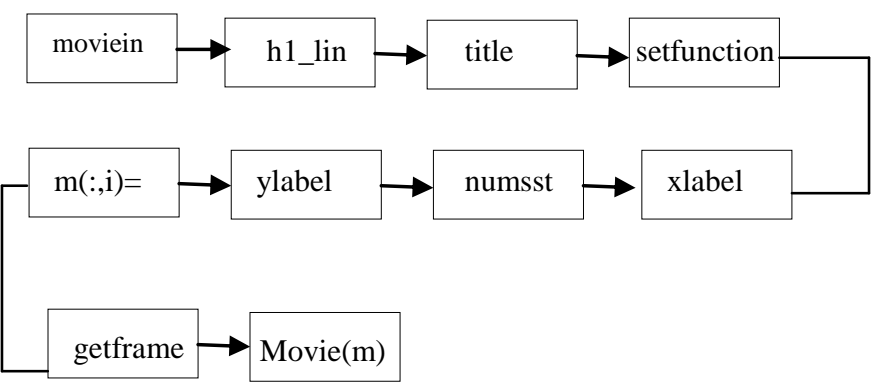

\subsection{Development of the Program}

$\mathrm{M}$-file movie in is set in place. Variable h1 holds information about the graph(s) that are generated and is called handle graphics. Command set used in the next line allows a user to manipulate a plot. This command takes as the input parameter the variable h1. Thickness of the plotted curves from the default value was maintained at 1.5 . This is subject to change. In the next line, we use command axis to customize plot. Axes chosen had their dimensions by default. Another important MATLAB function used in the file was get. It takes as the first input parameter a variable named' gca $=$ get' current axis. Variable $\mathrm{h}=$ get $($ gca...) is the graphics handle. The last command in the program was move (m) which tells MATLAB to play the movie just created and saved in column of the matrix.

\subsection{Steps of operations of the input functions}

MATLAB graphics tools were used to code a program that put a sequence of functional graphs in motion. Command 'movie' with scalar parameter k tells MATLAB that k frames are generated inside the loop 'for'. Each frame is stored in the column of the matrix ' $m$ '.

Trigonometric functions, hyperbolic, elliptic, parabolic and/or polar functions were used as inputs for the coding. The independent variable 'the angle' depicts the designs. The input functions were animated using the coded program. The movie (m) command commanded MATLAB to play the functional movie just created and saved in columns of the matrix $\mathrm{m}$. Several designs depending on the kth iterations were produced $(\mathrm{k}=1,2,3, \ldots)$.

\section{RESULTS}

As stated earlier, this work aimed at developing patterns for printing textiles of fabrics using mathematics and creating innovative designs using mathematics to serve as instructions for artistic, architectural and constructional work.

Some of the different types of designs developed are displayed below. Most of them serve as background designs in textiles and printing. Others are for embroidery, motifs and abstract logo designs, architectural designs, screen printing, sculpture pieces designs, weaving and knitting designs, general pattern designs, etc.

The classification of these designs are done with the mathematical functions used as sub headings.

\subsection{Integrated Polar Functions}

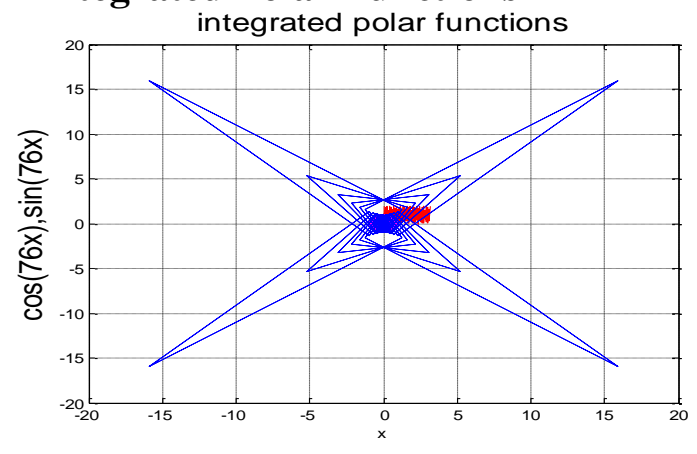

Figure 1: Motif for developing patterns/embroidery

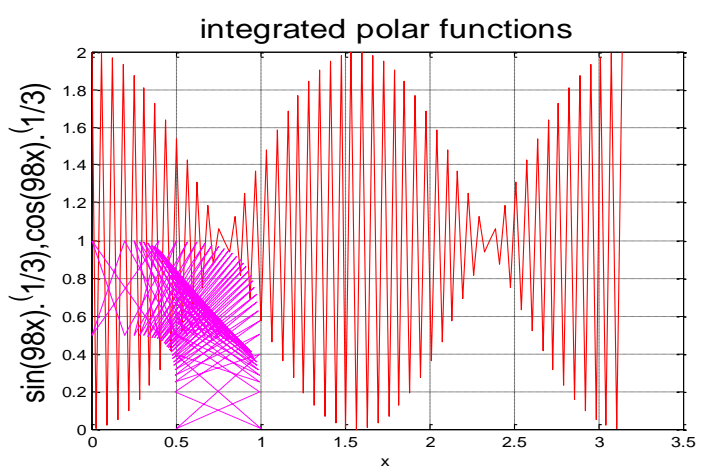

Figure 2: It serves as background pattern for fabrics or architectural design for floor tiles, ceiling patterns, gates 


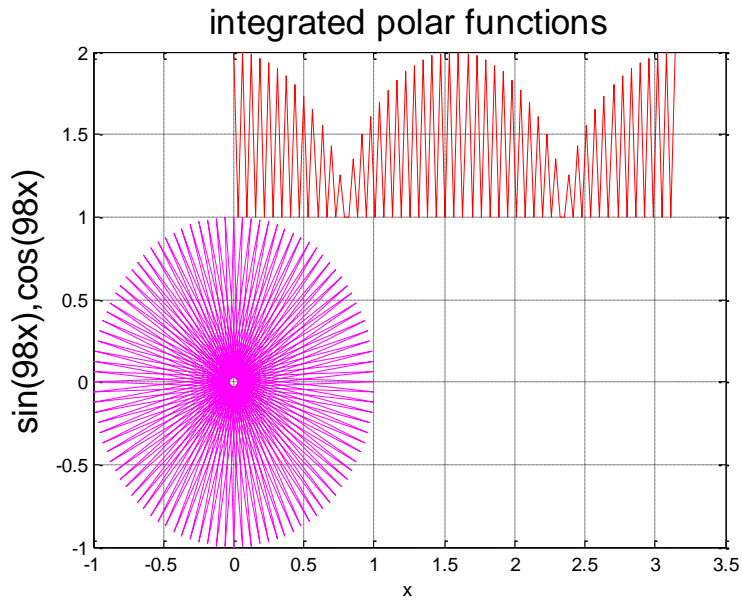

Figure 3: It serves as architectural design for fencing,/ ceiling or as embroidery or screen printing

\subsection{Trigonometric Functions}

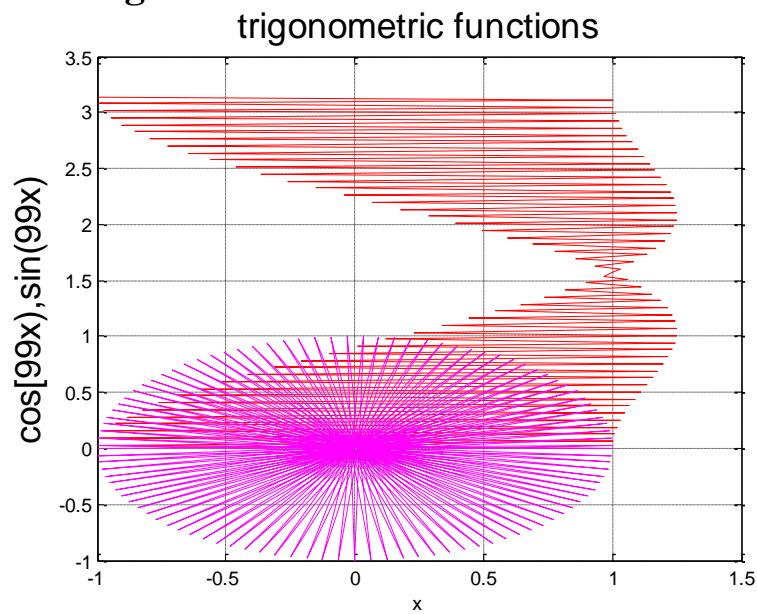

Figure 4: Patterns for basic design or constructional design

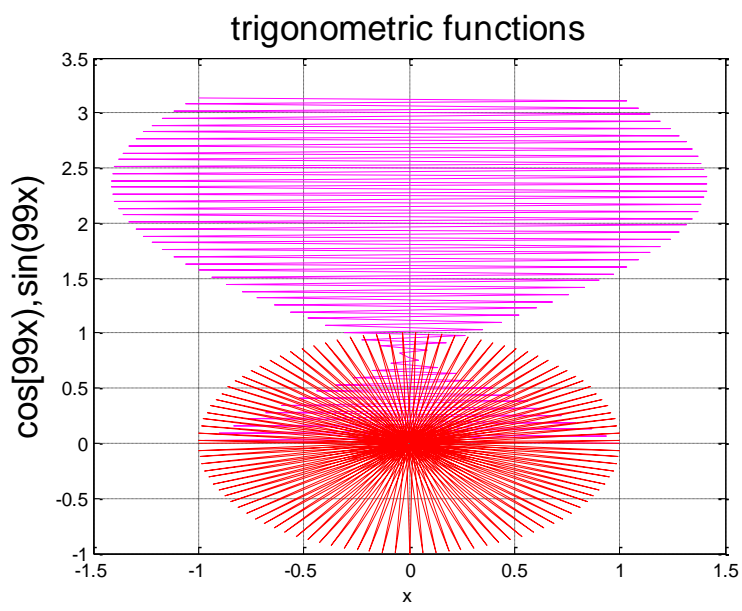

Figure 5: It serves as sculpture piece for football cups/other utility purposes like wine glass etc/for textile printing

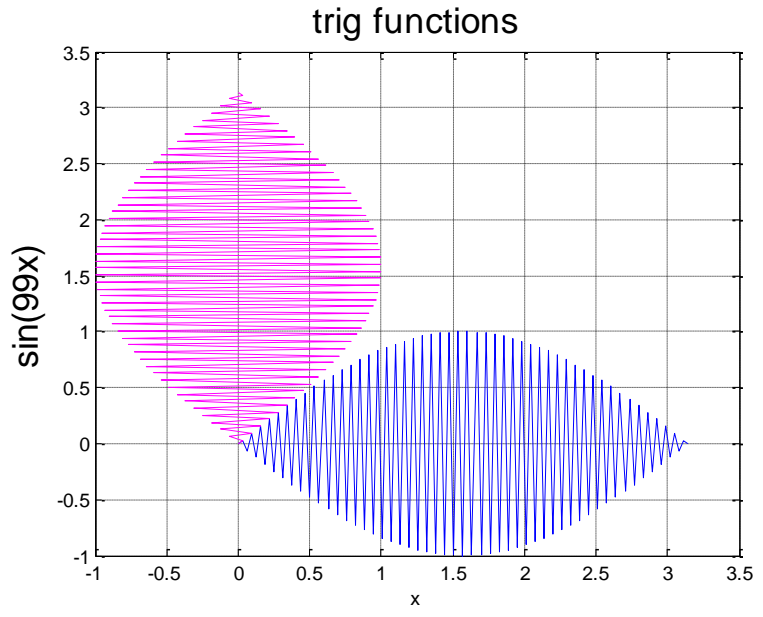

Figure 6:Pattern for textile printing

\subsection{Polar Functions}

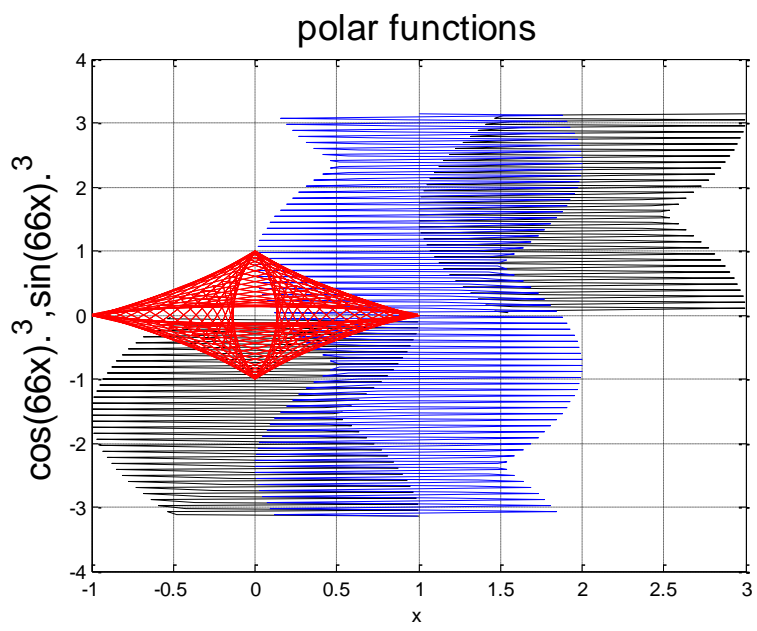

Figure 7: Pattern with lines/embroidery

\subsection{Ellipse}

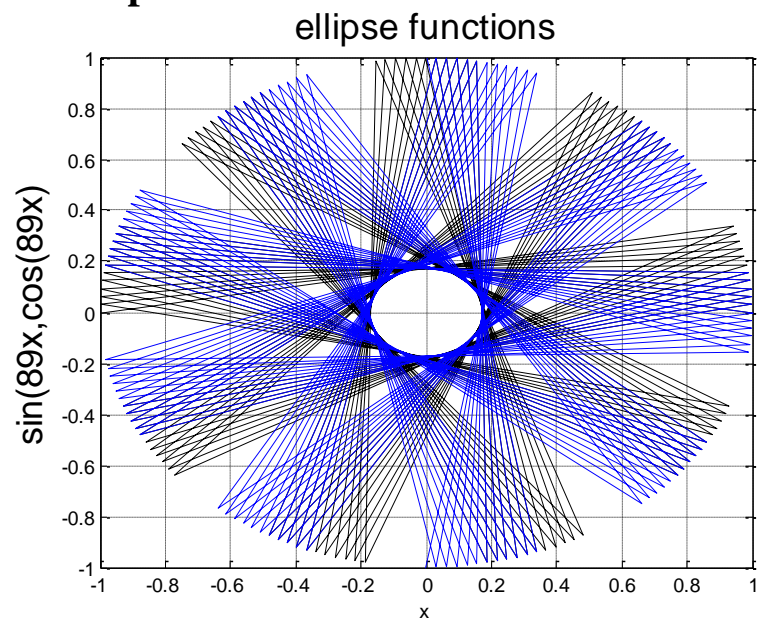

Figure 8: General pattern making / for textile printing/embroidery 


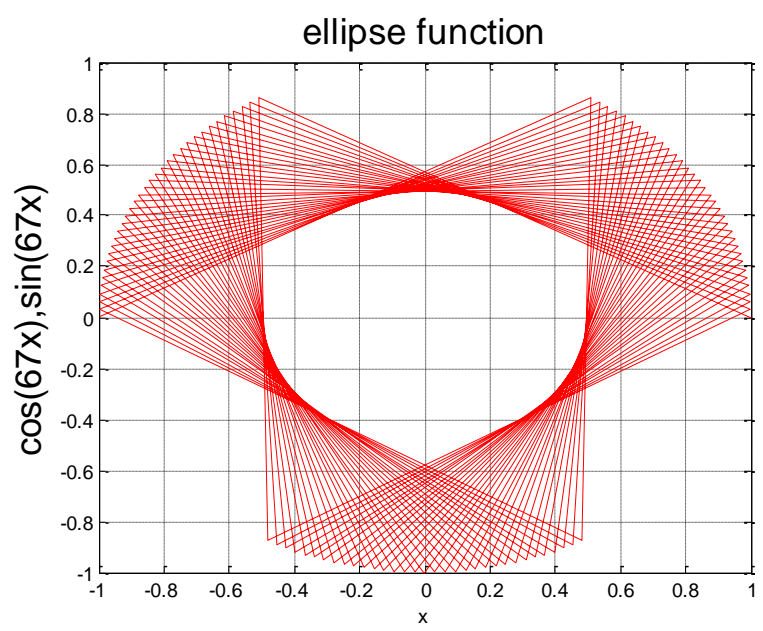

Figure 9: General pattern making/textile printing/embroidery ellipse function

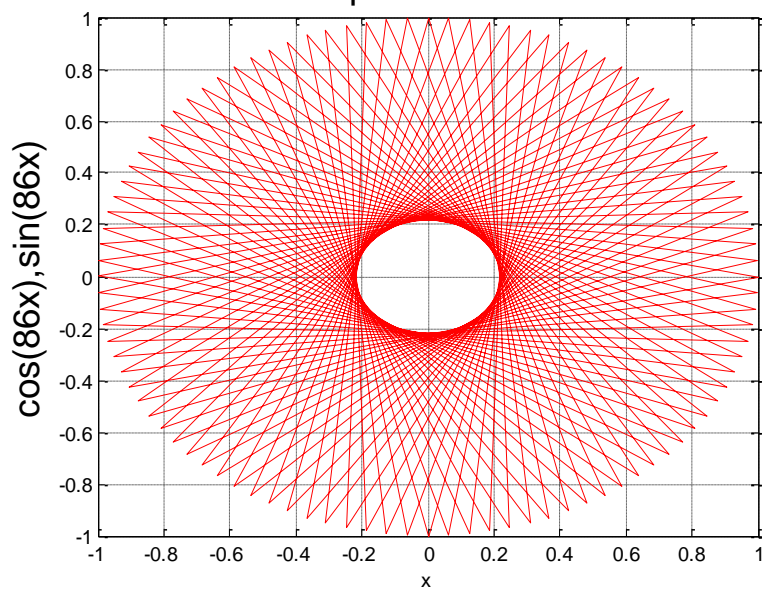

Figure 10: General pattern making/textile printing/embroidery

ellipse function

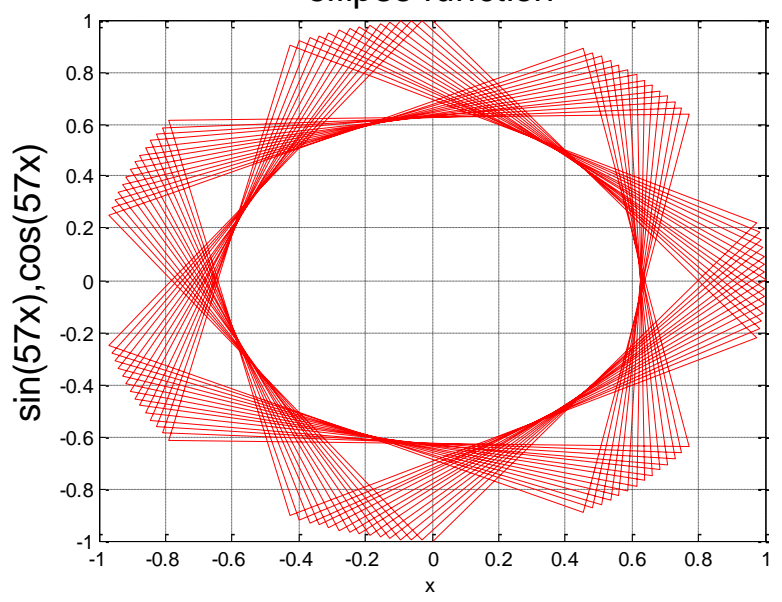

Figure 11: General pattern for fabrics/textile printing/embroidery

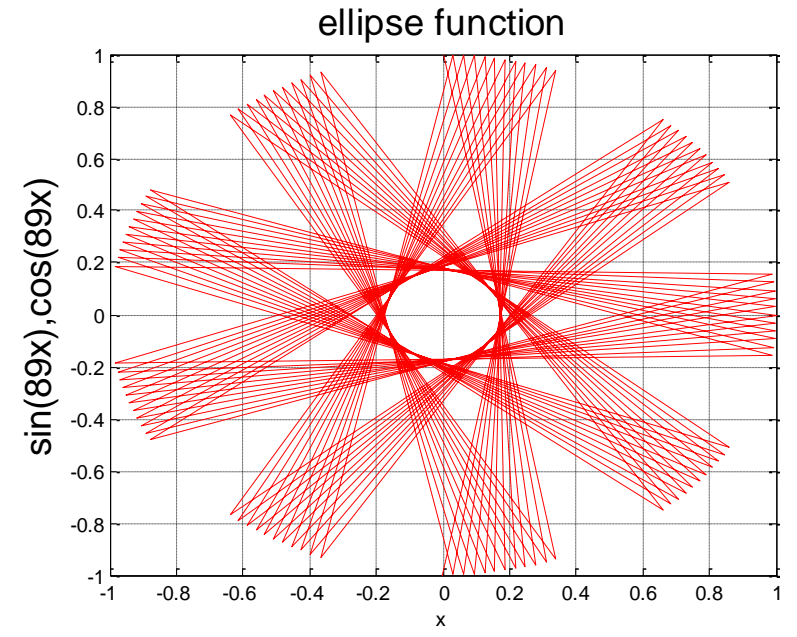

Figure 12: General pattern making/textile printing/embroidery

\subsection{Integrated Trig functions} integrated trig functions

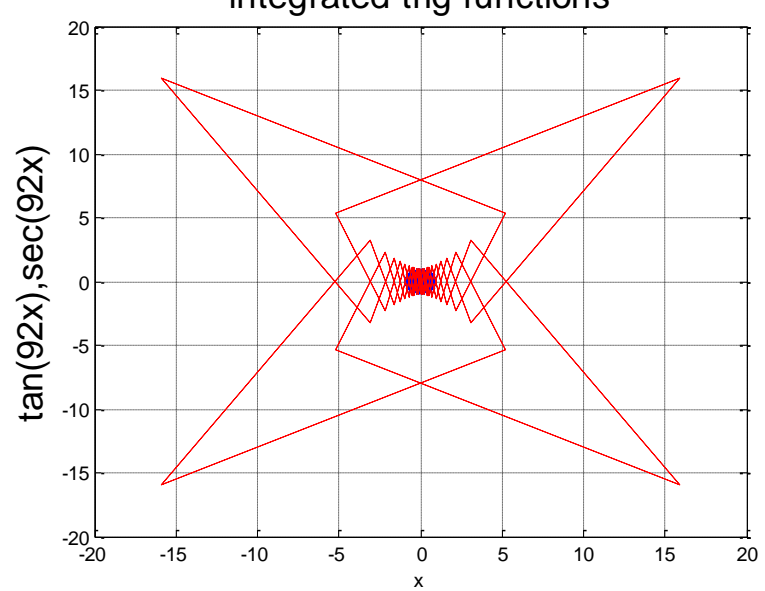

Figure 13: Serves as weaving/knitting or embroidery design

trigonometric functions $\mathrm{k}=1,2,3,4,5, \ldots, 100$

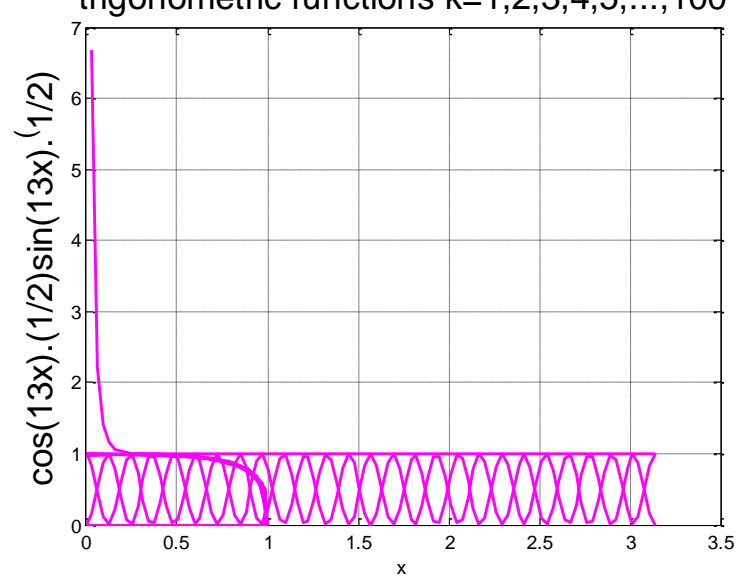

Figure 14: Embroidery or pattern making designs 
6.6 Trigonometry Functions trig functions

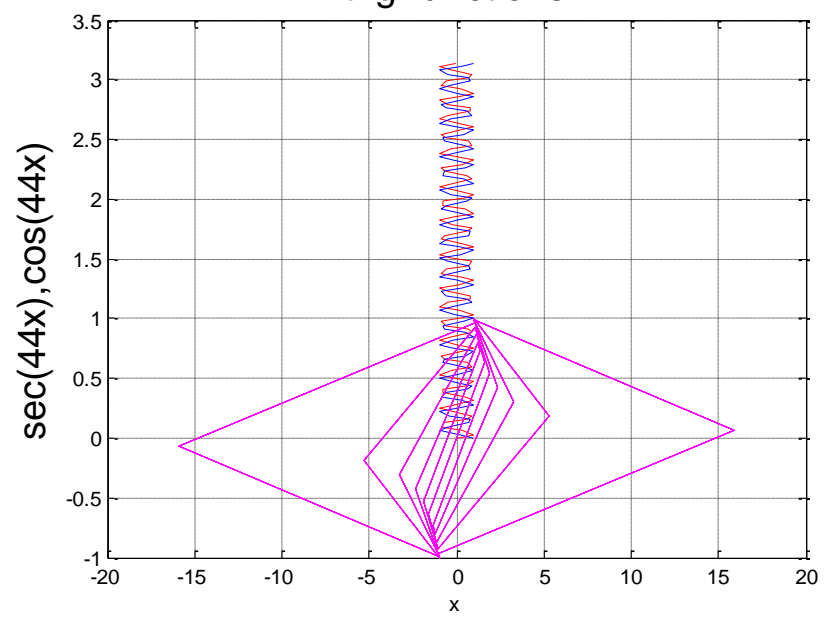

Figure 15: It serves as weaving/knitting or architectural design

trig functions

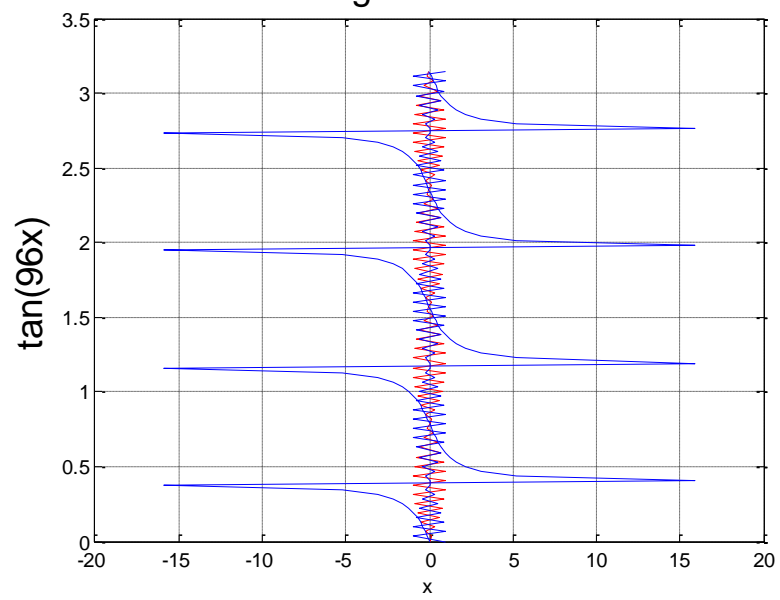

Figure 16: Serves as weaving/knitting or architectural design or embroidery

trig and conic section

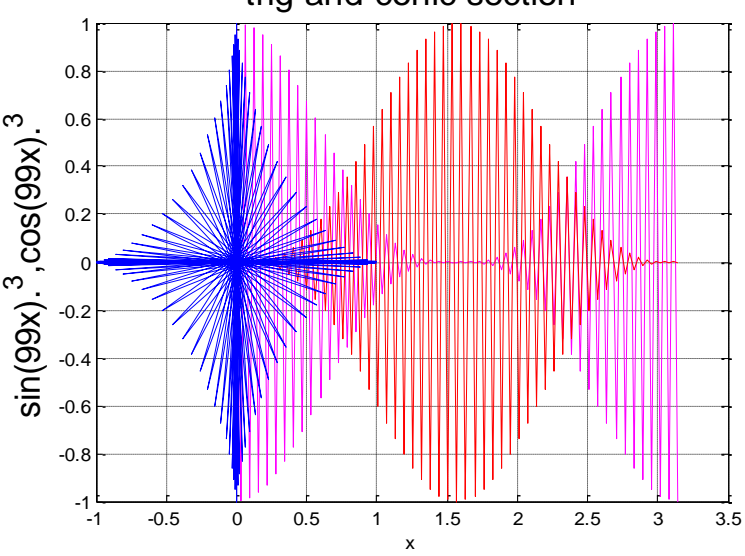

Figure 17:General pattern for textiles/fabrics/ for embroidery

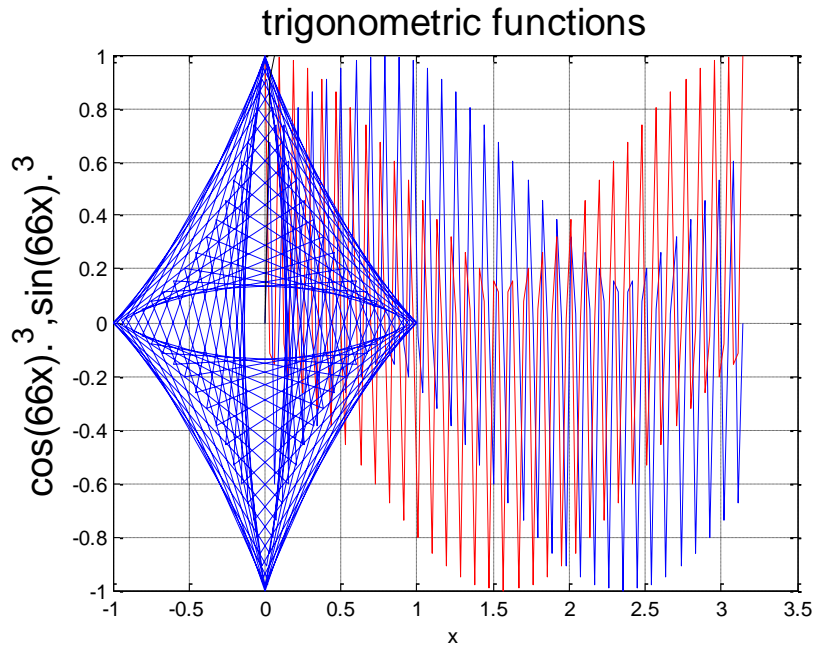

Figure 18: General pattern for textiles/fabrics/or as embroidery

trigonometric functions $\mathrm{k}=1,2,3,4,5, \ldots, 100$

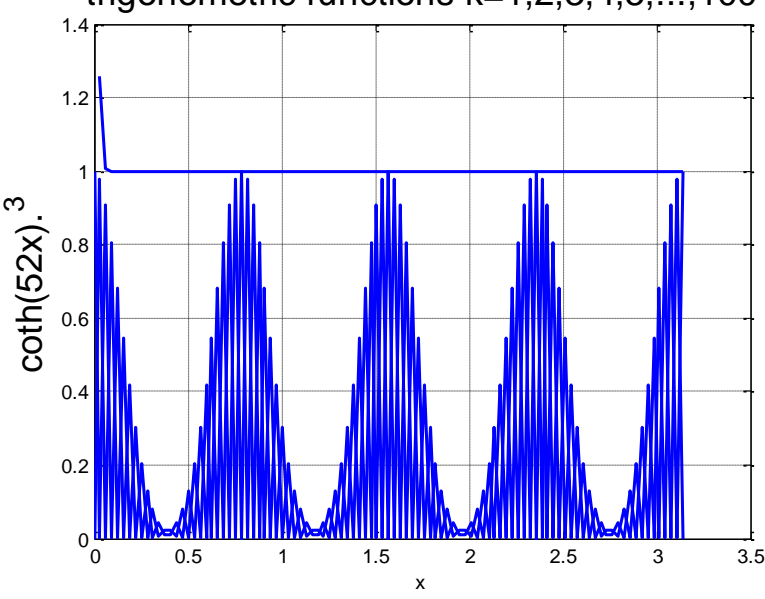

Figure 19:Textiles design or gates/louvres design or motifs

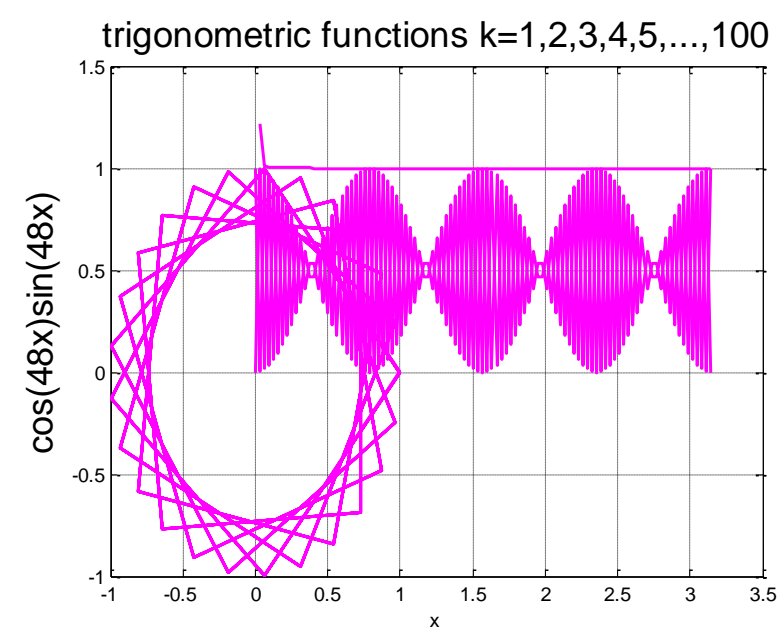

Figure 20: Weaving/background design/for embroidery/motif 


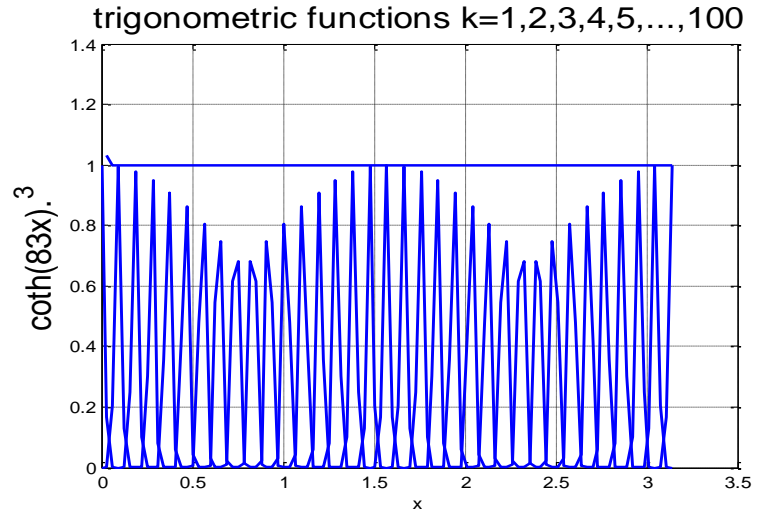

Figure 21: It serves as architectural design or motifs trigonometric functions $\mathrm{k}=1,2,3,4,5, \ldots, 100$

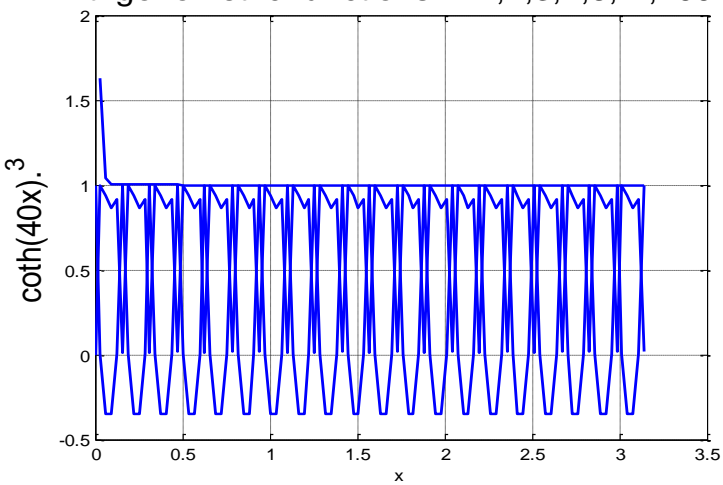

Figure 22: Windows/louvers design/inner room decoration/motifs

trigonometric functions $\mathrm{k}=1,2,3,4,5, \ldots, 100$

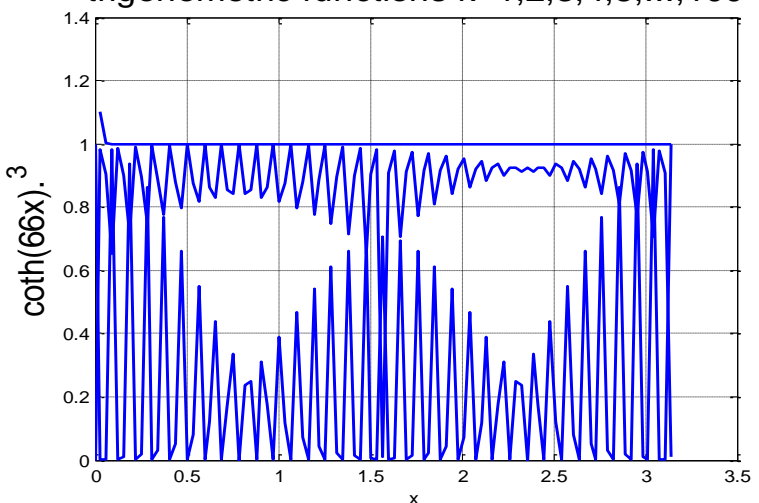

Figure 23:for textiles printing or gates/louvres design or motif

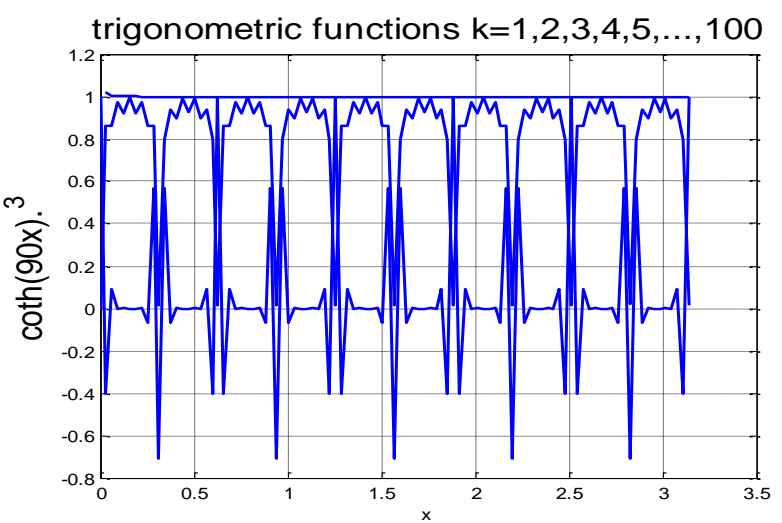

Figure 24:Pattern forTextiles/motifsles/gates/louvres

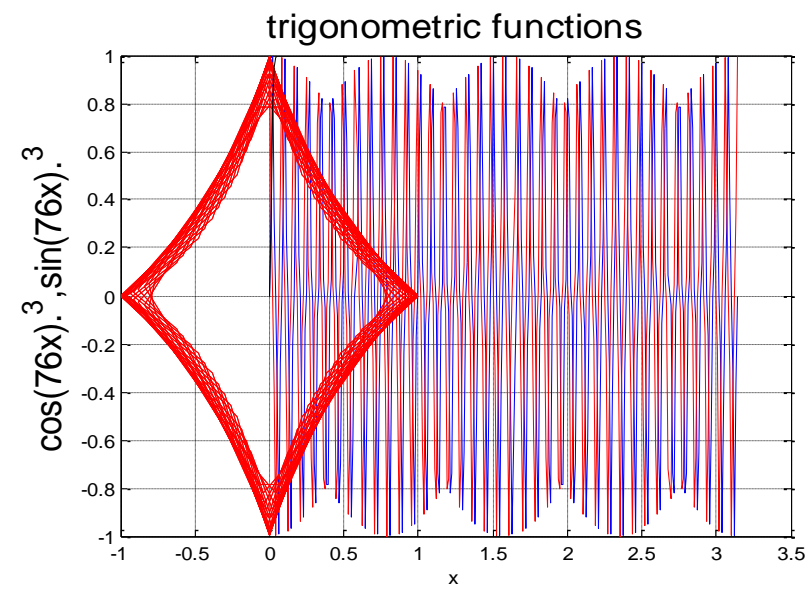

Fig 25: Background Designs for Textiles/ Pattern Making

\section{DISCUSSION}

\subsection{Embroidery}

Embroidery is patterns that are sewn onto clothes using threads of various colors. It is the handicraft of decorating fabrics or other materials with needle and thread or yarn. It may also incorporate other materials such as metal strips, pearls, beads etc. Embroidery is mostly used on caps, hats, coats, blankets, dress shirts, stocking, golf shirts etc. It can be seen in stitches such as chain stitch, blanket stitch and others. Most of the figures developed show Embroidery techniques such as counted-thread embroidery including cross-stitch and some canvas work methods like needlework lending themselves to geometric designs [15].

Figures such as figure 1, 3, 7, 8, 9, 10, 11, 12, 18, and 19 of the study serve as embroidery.

\subsection{Weaving and Knitting}

In knitting, weaving is a family of techniques used for several purposes in knitting. The most common use for the technique is when working strand color patterns in which two yarns are alternated to certain of the stitches to create patterns. Weaving is used to attach the horizontal strands of yarn behind stitches formed with the other yarn to the inside of the fabrics. Knitting is a method that is used to produce fabric by turning yarn into cloth. Knitted fabric consists of consecutive rows of loops through and existing loop. In weaving, fabrics are produced by interlacing two different sets of yarns or threads horizontally or vertically [9].

Figures 9, 11, 13, 15, 16, 22 and others serve as weaving and knitting.

\subsection{Textiles Printing}

Textile printing is the process of applying color to fabrics in definite patterns or design. In printing fabrics, the color is bonded with the fibre so as to resist washing and friction [6].

Figures 1, 5, 6, 7, 8, 9, 10, 11, 12, 21, 17, 18, 25, 19 and others serve as design for printing textiles.

\subsection{Motifs}

Motif is a design or pattern as decorations. Ornamental or decorative art can usually be analyzed into a number of different elements which can be called motifs. These may often as in textile art be repeated many times in a pattern. Many designs in Mosques in Islamic culture are motifs.

Figures such as figure 1, 19, 21, 22, 24 and others in the study serve as motifs. 


\subsection{Architectural/Constructional designs}

Architecture is the process and product of planning, designing and constructing buildings and other physical structures. It can mean the art and science of designing buildings and nonbuildings structures.

Figures such as figure 2, 4, 5, 14, 15, 16, 21 displayed above serve as instructional designs for architecture and construction work.

\section{CONCLUSION}

The research work generated beautiful mathematics designs and patterns which architects, artists and textile designers strive to achieve. Pattern Designs developed from the study should be used for textile printing. Architects and Artists should use the designs as instructional guide for their constructional works and artistic works respectively. It is therefore hope to explore textile designs that depict Ghanaian cultural essence using mathematics for the future work.

\section{ACKNOWLEDGMENTS}

Our thanks to Matlab Makers whose graphic tools were instrumental in developing the designs. Also our gratitude goes to Professor Clement Somuah who has encouraged us towards the development of this research work.

\section{REFERENCES}

[1] Barchfield, J. (2010). Fashion and Advanced Mathematics Meet at Miyake, ABC News

[2] Belcastro, Sarah-Marie; Carolyn, Yackel, eds. (2007). Making Mathematics with Needlework: Ten Papers and Ten Projects, A K Peters, ISBN 1-56881-331-7

[3] Bajardi, M. (2010). Textile, morganbajardi.blogspot.com /2010_05_01_archive.html. [accessed on 24/06/2015; $3: 45]$

[4] Dietz, A. K. (1949). Algebraic Expressions in Handwoven Textiles (PDF), Louisville, Kentucky: The Little Loomhouse

[5] DMCK Designs@ 30, October, 2013. Mathematical Fashion https://dmck.us/
[6] Gillow, John, and Bryan Sentance. World Textiles, Little, Brown, 1999.

[7] Gupta A. (2010). Applying Mathematics to Web Design. http://www.smashingmagazine.com/2010/02/09/applying -mathematics-to-web-design/ [accessed on 24 June 2015 $3: 43 \mathrm{pm}]$

[8] H.-D. Cao and X.-P. Zhu, "A complete proof of the Poincar e and Geometrization Conjectures - application of the Hamilton-Perelman theory of the Ricci flow", Asian Journal of Math. 2006, p. 165-49

[9] June H. H. (2012). The principles of Knitting, Simon and Schauster, pp 2160-263, 344-349

[10] King J. A, (2005). Interior designer at SMRT Inc, LEED $\mathrm{AP}$ ID $+\mathrm{C}$.

[11] Marchand P., Graphics and GUIs with MATLAB, second edition, CRC press,Boca Raton, 1999

[12] Math and Art conference proceedings (2007 and 2008). www.mathartfun.com/shopsite [accessed on 24 June 2015; 4:32pm]

[13] Miller, J. C. P. (1970). "Periodic forests of stunted trees", Philosophical Transactions of the Royal Society of London, Series A, Mathematical and Physical Sciences 266 (1172): 63111,Bibcode:1970RSPTA.266...63M,doi:10.1098/rsta.19 70.0003, JSTOR 73779

[14] Miyake (2010). Design Studio. The Maths of Miyake (wired UK)-Wired.co.uk

[15] Taimina, D. (2009). Crocheting Adventures with Hyperbolic Planes, A K Peters, ISBN 1-56881-452-6

[16] Van Niekerk Di. (2006). A perfect world in Ribbon Embroiery and Stumpwork

[17] Williams, Elsa S. Bargello: Florentine Canvas Work. Van Nostrand Reinhold, 1967. 